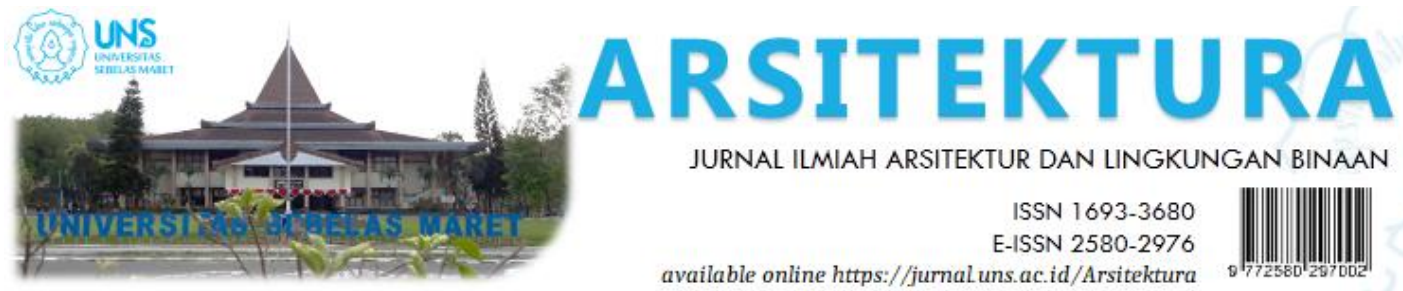

Volume 19 Issue 1 April 2021, pages:37-50

\title{
Translokalitas Budaya Sorkam pada Penggunaan Ruang untuk Kegiatan sehari-hari Masyarakat di Perumahan Bumi Yapemas Indah, Bekasi
}

\section{The Translocality of Sorkam Culture on The Use of Space for Community's Everyday Life in Bumi Yapemas Indah Gated Community, Bekasi}

\author{
Heidi Aisha ${ }^{1 *}$, Agus S. Ekomadyo ${ }^{2}$ \\ Program Studi Magister Arsitektur, Sekolah Arsitektur, Perencanaan dan Pengembangan Kebijakan \\ (SAPPK), ITB ${ }^{1 *}$ \\ heidiaishapasaribu@gmail.com \\ Kelom pok Keahlian Perancangan Arsitektur, Sekolah Arsitektur, Perencanaan dan Pengembangan \\ Kebijakan(SAPPK), ITB ${ }^{2}$
}

DOI: https://doi.org/10.20961/arst.v19i1.48283

Received: February 3,2021 Revised: April 3,2021 Accepted: April 5,2021 Available online: April 30,2021

\begin{abstract}
Indonesia has various ethnic societies that have been migrated from their origin places and settled in other regions. It also occurs where Sorkam community, a coastal ethnic communities originalle placed in Central Tapanuli, North Sumatra, have moved and settled in Bumi Yapemas Indah Housing, South Tambun, Bekasi Regency. This article discusses how specific ethnic communities lives in a modern gated-community in everyday life. It examines how communities using space in everyday lives and and their cultural forms is maintained in translocal living spaces. By Lefebvre's rhythmanalysis approach, research is conducted with interviews with community leaders and a sample of residents, and also field observation. It is found that the traditional culture of the Sorkam people didnot have a direct effect on the architecture and use of space, but the similarity in the culture of the community encouraged the interaction between the rhythms of people's lives. Cultural similarity encourages interaction between the rhythms of people's lives so that the phenomenon of space use is reinforced according to the Eurhythmia concept. The phenomena of using the space include: 1) the emergence of a sense of security and comfort in using spaces 2) utilization of indoor and outdoor spaces as a social space, and 3) adjustment of space according to the culture of the local community. It is hope this article will contribute to the studies of social production of space by specific community.
\end{abstract}

Keywords: translocal, ethnic communities, settlements, Lefebvre, rhythmanalysis.

\section{PENDAHULUAN}

Merantau merupakan proses seseorang pergi dari tempat asalnya untuk menjalani kehidupan di daerah lain. Di tempat baru tersebut para perantau menetap dan beradaptasi dengan lingkungan setempat guna menjalani kehidupan dengan nyaman. Namun begitu masing-masing komunitas tetap mencoba untuk melestarikan budaya mereka sebagai upaya mempertahankan ikatan dengan kampung halamannya. Upaya tersebut justru 
membentuk identitas baru namun tetap terhubung dengan asal-usulnya. Hubungan antara identitas baru dengan lama tersebut dapat diartikan sebagai hubungan translokal (Low, 207; Madaville, 2004). Di tempat tersebut terbentuk ruang yang meleburkan batas identitas tersebut sehingga disebut sebagai ruang translokal. Ruang ini mencakup pengalaman maupun materialitas dari kehidupan sehari-hari dari berbagai tempat. Ruang translokal ini merupakan bagian dari jaringan lokalitas yang dibagi bersama oleh keluarga, lingkungan, kelompok, ataupun suatu komunitas (Low, 2017). Konsep translokal ini dapat digunakan untuk mengeksplorasi transformasi ruang-ruang urban tradisional menjadi tempat dengan keragaman budaya (Low 2017).

Fenomena ini telah terjadi sejak lama dan dapat dilihat dari banyaknya kampung etnis yang berkembang sejak zaman Nusantara. Selain itu, fenomena perpindahan etnis tertentu secara masif dapat dilihat dari fenomena berkembangnya masyarakat etnis Jawa dan Bali yang tersebar di beberapa pulau seperti Kalimantan, Sumatera, Sulawesi, dan Sumbawa akibat program transmigrasi dari pemerintah. Telah ada beberapa penelitian yang mengkaji hubungan fenomena merantau dengan transformasi ruang-ruang bermukim di Indonesia. Dalam penelitiannya mengenai adaptasi arsitektur tradisional Bali di Desa Balinuraga, Ata \& Ekomadyo (2018) menjelaskan bahwa warga Desa Balinuraga merupakan masyarakat suku Bali Etnis Penida yang masih mempertahankan budaya tanah leluhur mereka dengan cara menyesuaikan aturan-aturan yang mereka bawa terhadap kondisi lingkungan yang berbeda sehingga menghasilkan permukiman dengan karakter yang kuat. Salah satu penyesuaian yang dilakukan warga Desa Balinuraga yaitu dengan menerapkan prinsip asta kosala-kosali pada tempat komunal di desa tersebut. Berbeda dengan temuan di Desa Balinuraga, dalam penelitiannya mengenai fasad bangunan di Kampung Arab Pekojan, Jakarta Barat, Kurniadi \& Utami (2016) menjelaskan bahwa karakter etnis Arab pada permukiman tersebut kurang terlihat walaupun sebelumnya diperkirakan memiliki potensi dalam pembentukan kawasan yang berkarakter mengingat sejarah perkembangan kawasan sebagai tempat tinggal khusus bagi komunitas Arab yang telah berkembang sejak abad 16 (Nasser \& Sulasman, 2018; Wahyudi \& Madjid, 2019). Penurunan karakter kawasan ini terjadi karena menurunnya jumlah populasi komunitas masyarakat etnis Arab di kampung tersebut (Ellisa, 2008) dan banyaknya bangunan baru dengan elemen-elemen fasade yang lebih modern menggantikan bangunan lama.

Dalam konteks permukiman modern, fenomena serupa juga dapat ditemukan pada permukiman real estate dengan target konsumen dari kelompok budaya tertentu. Contohnya perumahan-perumahan berkonsep Islami di kawasan sekitar Jakarta (Jabodetabek) dengan target konsumen keluarga kelas menengah beragama Islam (Weng, 2018). Perumahan ini umumnya termasuk ke dalam tipologi perumahan berpagar (gated-community). Menurut Weng (2018), perumahan Islami ini memiliki pengaturan ruang yang berbeda dari perumahan berpagar pada umumnya. Perumahan Islami umumnya memiliki masjid yang ditempatkan dekat dengan gerbang perumahan. Masjid ini tidak hanya digunakan untuk kegiatan keagamaan namun juga digunakan sebagai ruang interaksi sosial yang meningkatkan rasa kepemilikan komunitas diantara penghuni. konsep Islami juga diterapkan dalam perancangan unit rumah, seperti perletakkan toilet yang tidak boleh diletakkan menghadap kiblat. Beberapa perumahan juga dilengkapi dengan fasilitas yang menerapkan konsep Islami, seperti kolam renang dengan zona terpisah untuk laki-laki dan perempuan, pusat pembelajaran Islam, sekolah Islam dan lainnya.

Adapula permukiman modern dengan target konsumen dari komunitas etnis tertentu, salah satunya Perumahan Bumi Yapemas Indah di Kabupaten Bekasi. Perumahan yang telah berdiri dari tahun 1997 ini awalnya dibangun untuk menampung para perantau etnis pesisir dari Sorkam, salah satu kecamatan di Tapanuli Tengah. Para perantau ini menetap di membentuk komunitas di perumahan tersebut yang masih bertahan hingga saat ini. Penelitian ini bertujuan untuk menelusuri bagaimana masyarakat Sorkam tersebut menggunakan 
ruang dalam keseharian mereka, Dari keseharian tersebut, penulis mengidentifikasi nilai-nilai budaya masyarakat Sorkam yang masih dipelihara penghuni dan bagaimana budaya masyarakat membentuk ruang bermukim mereka di Perumahan Bumi Yapemas Indah hingga menjadi ruang translokal. Penelusuran menggunakan pendekatan rhytmanalysis dari sosiolog Marxis dan filsuf urban Henry Lefebvre.

Rhytmanalysis merupakan cara untuk mempelajari aktivitas sehari-hari dan cara mereka terungkap melalui ruang dan waktu (Alhadeff-Jones, 2019). digunakan untuk menguraikan dan menganalisis ritme dalam suatu ruang dan efek ritme tersebut pada penghuninya. Lefebvre membayangkan analisis ritme sebagai metode sosiologis untuk mempelajari jalinan hubungan dan interaksi temporalitas sosial pada masyarakat industri, seperti yang ditentukan oleh ritme siklik (misalnya pergantian siang malam) dan ritme linier, seperti pengulangan perakitan baris yang monoton. (Alhadeff-Jones, 2019; Revol 2014).

Lefebvre menjabarkan rhythmanalysis ke dalam empat konsep, yaitu eurhythmia, arrhythmia, polyrhythmia, dan isorhythmia. Eurhythmia mengGambarkan interaksi konstruktif antar dua atau lebih ritme yang saling beresonansi dan menguatkan fenomena ritmis yang terjadi. Arrhythmia mengGambarkan konflik atau ketidaksesuaian antara dua atau lebih ritme, ditandai kurangnya sinkronisasi dan dapat berakhir pada hilangnya ritme yang terjadi (Alhadeff-Jones, 2018). Polyrhythmia mengGambarkan ritme heterogen dari kehidupan berdampingan secara bersamaan tanpa bertentangan dan tanpa terkoordinasi satu sama lain dalam satu lingkungan. Isorhythmia mengGambarkan kesetaraan dan keseimbangan ritme, dicapai saat lingkungan berada dalam harmoni sepenuhnya (Lefebvre, 2004).

Pendekatan rhythmanalysis juga digunakan dalam berbagai penelitian terkait ruang dan etnografi. Peng-Lee (2016) menggunakan rhythmanalysis untuk meneliti kelompok masyarakat (seperti pengungsi, pekerja migran, profesional) yang mana tidak mungkin untuk melakukan kerja lapangan etnografi tradisional karena kesulitan akses atau ketika suatu peristiwa (seperti migrasi) telah terjadi. Lyon (2016) menangkap atmosfir ruang di Billingsgate, pasar ikan grosir London dengan menganalisis ritme kehidupan sehari-hari di sana. Nash (2018) menggunakan rhythmanalysis untuk mengeksplorasi bagaimana pekerja di Kota London memahami dan memaknai tempat mereka bekerja sebagai bagian dari identitas mereka. Alhadeff-Jones (2019) mengeksplorasi pengaruh konfigurasi spasial dan temporal terhadap kemampuan orang dewasa untuk belajar menggunakan pendekatan rhythmanalysis.

Pendekatan rhytmanalysis masih belum banyak digunakan dalampenelitian dengan lingkup arsitektur dan ruang binaan khususnya di Indonesia. Pendekatan ini berpotensi membantu peneliti menguraikan karakteristik dari ruang dan pengguna berdasarkan ritme aktivitas di dalamnya. Diharapkan penelitian ini berkontribusi pada pengetahuan mengenai karakter dan adaptasi dalam permukiman berbasis komunitas etnis tertentu, dan juga menjadi referensi dalam pengembangan pendekatan rhythmanalysis dalam penelitian terkait lingkungan binaan di Indonesia.

\section{METODE}

Metode yang digunakan dalam penelitian ini adalah deskriptif-kualitatif (Kumar, 2018). Pengumpulan data dilakukan dengan metode observasi dan wawancara. Observasi dilakukan selama 3 hari dari tanggal $9-11$ November 2020 untuk melihat keseharian masyarakat dan pengaruhnya terhadap ruang bermukim. Observasi dilakukan dengan berjalan kaki mengelilingi kawasan Perumahan Bumi Yapemas Indah sebanyak tiga putaran (pagi, siang, dan malam) dengan sesekali berhenti untuk mengambil foto. Metode ini dinilai efektif untuk menangkap dan merasakan ritme kehidupan yang terjadi di lingkungan sekitar (Nash, 2018). Untuk mengidentifikasi kegiatan masyarakat diluar observasi dilakukan wawancara kepada lima tokoh masyarakat dan lima sampel warga setempat. Metode pemilihan sampel yang digunakan adalah snowball sampling (Kumar, 2018) yang mana sampel 
didapatkan dari jejaring tokoh yang direkomendasikan oleh responden yang ditemui pertama kali.

Data yang telah dikumpulkan dianalisis dengan pendekatan rhythmanalysis. Pendekatan rhythmanalysis yang digunakan berfokus pada konsep eurhythmia yang mengGambarkan interaksi antar ritme yang terjadi dalam ruang yang diamati. Konsep eurthythmia digunakan untuk menjelaskan keseharian masyarakat dan fenomena- fenomena penggunaan ruang yang ditemukan dari pengambilan data. Fenomenafenomena tersebut kemudian digunakan untuk menjelaskan Perumahan Bumi Yapemas sebagai ruang translokal yang terbentuk di tengah kabupaten Bekasi.

\section{HASIL DAN PEMBAHASAN}

\subsection{Deskripsi Perumahan Bumi Yapemas Indah dan Keberadaan Masyarakat Sorkam}

Bumi Yapemas Indah merupakan perumahan yang terletak di RW 09 Desa Sumber Jaya, Kecamatan Tambun Selatan, Kabupaten Bekasi. Perumahan terdiri atas $1 \mathrm{RW}$ yang di dalamnya terdapat 7 RT. Perumahan seluas 4,5 hektar ini ditempati oleh 139 kepala keluarga dengan mayoritas $80 \%$ warga etnis pesisir asal Sorkam dan sekitarnya (Gambar 1). Etnis Pesisir sendiri merupakan penduduk Minangkabau yang bermigrasi ke Tapanuli Tengah sejak abad ke-14 dan telah bercampur dengan suku Melayu, Mandailing, Aceh, dan Batak. Etnis pesisir tersebar di beberapa daerah di kabupaten Tapanuli Tengah, seperti Barus, Sorkam, dan kota Sibolga (Sinar, Tandjung \& Putra, 2010). Saat ini, etnis pesisir telah merantau ke seluruh penjuru Indonesia terutama ke daerah Jabodetabek.

Eddy Suwandy Pasaribu adalah seorang tokoh masyarakat berusia 63 tahun, ketua RW 09 Desa Sumber Jaya. Menurut beliau perumahan ini mulai dibangun dari tahun 1997 oleh pengembang asal Sorkam, Misri Pasaribu. Atas inisiatif beliau, perumahan Bumi Yapemas dibuat dengan cicilan yang ringan dan dipasarkan pada masyarakat Sorkam baik yang sudah merantau ke sekitar Jakarta maupun yang baru berniat untuk merantau dari
Sorkam. Sejak perumahan tersebut dibuka, banyak masyarakat Sorkam dan daerah sekitarnya (Barus, Sibolga) yang membeli dengan cicilan dan langsung menempati perumahan tersebut hingga sekarang. Beliau juga menuturkan bahwa saat dibangun daerah Tambun Selatan masih kosong, masih berupa desa dengan beberapa rumah warga setempat, sekarang daerah ini sudah padat dan dilengkapi sarana prasarana yang memadai.

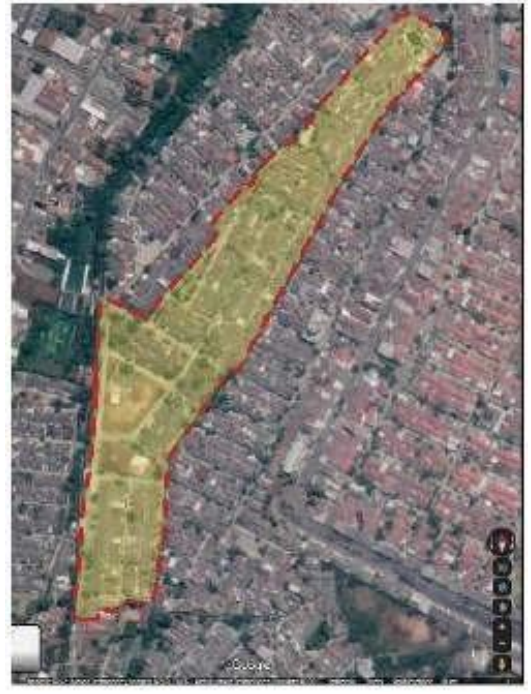

Gambar 1. Deliniasi Perumahan Bumi Ya pemas Indah, Sumber: Google Maps dengan disesuaikan penulis, 2020

\subsection{Arsitektur Perumahan Bumi Yapemas Indah}

Perumahan Bumi Yapemas Indah termasuk ke dalam tipologi perumahan berpagar (gated- community). Hal tersebut terlihat dari akses masuk perumahan yang hanya melalui gerbang dari Jalan Utama Bumi Yapemas Indah (Gambar 2). Perumahan ini dibangun dengan model pengembangan real estate sehingga dilengkapi dengan berbagai fasilitas sarana prasarana serta utilitas yang lengkap. Penataan kavling rumah menyesuaikan bentuk lahan yang memanjang dengan fasilitas umum diletakkan di beberapa titik yang tersebar pada tapak (Gambar 3). 


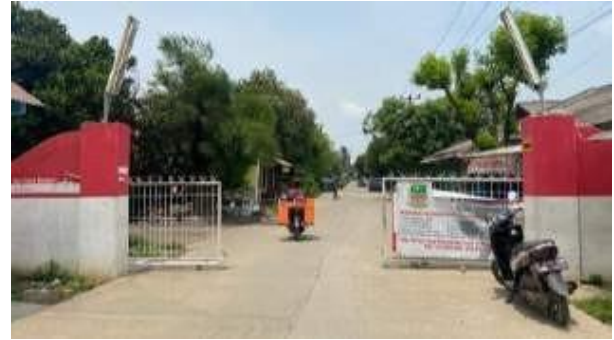

Gambar 2. Gerbang masuk Perumahan Bumi Yapemas Indah

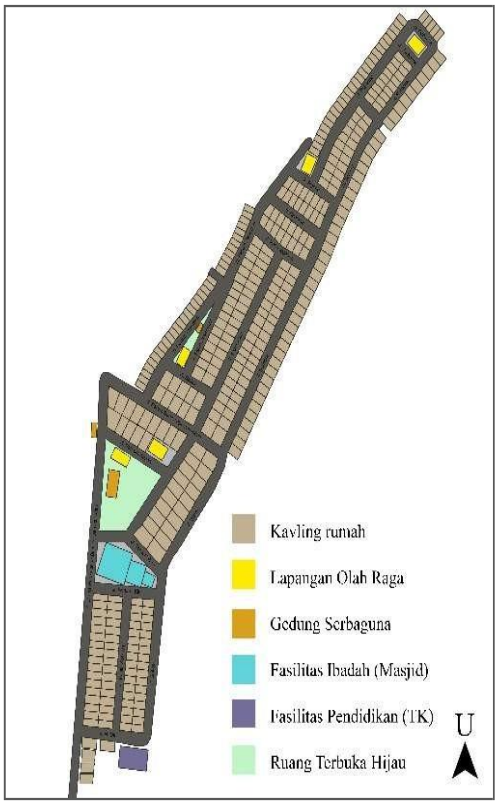

Gambar 3. Peta Sederhana Perumahan Bumi Yapemas Indah

Rumah tradisional dari etnis pesisir di Tapanuli Tengah sendiri berbentuk rumah panggung yang serupa dengan rumah tradisional etnis Melayu (Gambar 4). Rumah tradisional ini pun sudah jarang ditemukan di tempat asalnya. Namun dari hasil pengamatan, tidak ditemukan jejak arsitektur tradisional pada bentuk rumah karena pengembang mengadopsi tipe rumah sangat sederhana standar yang biasa dibangun oleh para pengembang. Di awal pembangunan perumahan, pengembang membangun tiga tipe rumah, yaitu tipe 27, tipe 36, dan tipe 54 (Gambar 5). Seiring waktu, para penghuni pun merenovasi rumah mereka, baik mengatur ulang tata letak atau menambahkan ruangan di dalam rumah maupun mengubah tampak bangunan sesuai dengan selera ataupun tren yang sedang berlangsung. Hal tersebut membuat hilangnya keseragaman wajah bangunan (Gambar 6).

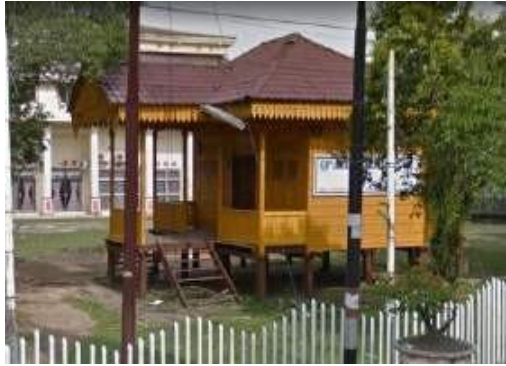

Gambar 4. Replika rumah panggung khas etnis pesisir Tapanuli Tengah

Sumber: Google Street, 2020

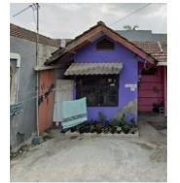

(a)

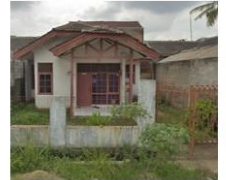

(b)

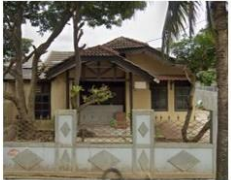

(c)
Gambar 5. Rumah tipe 27 (a), tipe 36 (b), dan tipe 54 (c) di Perumahan Bumi Yapemas Indah
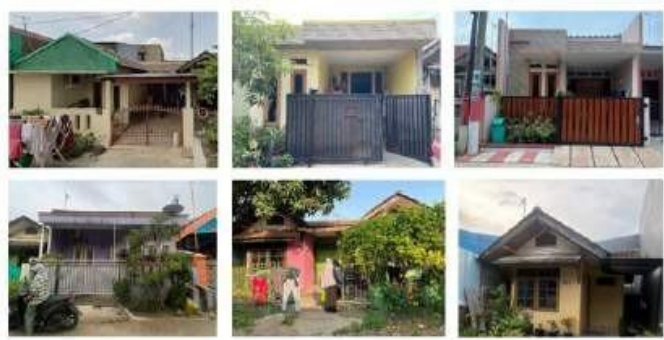

Gambar 6. Tampak rumah-rumah di Perumahan Bumi Yapemas Indah

\subsection{Budaya Masyarakat Sorkam di Perumahan Bumi Yapemas Indah}

Di dalam perumahan Bumi Yapemas Indah tercipta komunitas masyarakat dengan budaya dan kebiasaan yang terbawa dari kampung halaman. Adat istiadat etnis pesisir merupakan perpaduan antara adat Minang dan Batak serta ajaran Islam (Sinar, Tandjung \& Putra, 2010), yang terlihat pada perpaduan bahasa Batak dan Minangkabau yang menjadi bahasa etnis ini. Salah satu kebudayaan yang masih dilestarikan di daerah tersebut salah satunya kesenian Sikambang, berupa tarian dengan musik dan nyanyian tradisional yang biasa ditampilkan dalam acara-acara perayaan dalam masyarakat, salah satunya acara pernikahan (Gambar 7). 
Selain itu, masyarakat etnis pesisir memiliki tali persaudaraan yang kuat serta menjunjung tinggi nilai agama Islam (Sinar, Tandjung \& Putra, 2010). Hal tersebut terlihat dari adanya kegiatan-kegiatan rutin yang dilakukan masyarakat. Kegiatan tersebut diantaranya yaitu fardu kifayat dan pengajian rutin. Fardu kifayat merupakan pengurusan pemakaman masyarakat setempat yang dilakukan secara gotongroyong. Adapun pengajian rutin yang dilakukan seminggu sekali di rumah warga.

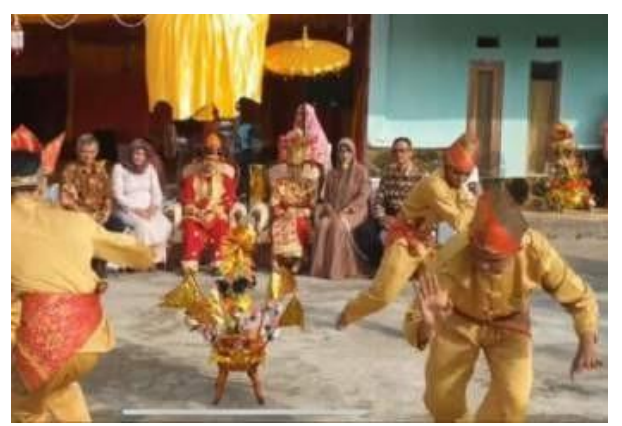

Gambar 7. Kesenian Sikambang yang ditampikan pada pernikahan a dat pesisir

Sumber:

https://www.youtube.com/watch?v=Lxy W_v K3_b k, diambil pada tanggal 7 November 2020

\subsection{Ritme Keseharian Permukiman Bumi Yapemas}

Lefebvre memahami gagasan ritme sebagai cara untuk mempelajari aktivitas sehari-hari dan cara mereka terungkap melalui ruang dan waktu (Alhadeff-Jones, 2019). Ruang sendiri merupakan wadah manusia beraktivitas dan melakukan pergerakan sehingga dalam mengartikan ruang kita tidak bisa mengartikannya secara terpisah (Tuan, 1977). Dengan mengamati ruang, aktivitas, dan waktu secara berdampingan, maka didapat ritme dari kehidupan dari penggunaan ruang tersebut.

Menurut penuturan Sahraini (48 tahun) yang sehari-hari berada di rumahnya di blok $\mathrm{C} 3$ no. 33 (RT 01), saat pagi hari, mulai dari jam 7 hinga 10 pagi, jalan dalam perumahan ramai dengan para anak-anak yang berjemur dan ibuibu yang menjaga anak mereka (Gambar 8). Jalan menjadi ruang publik informal yang dimanfaatkan warga untuk saling berinteraksi. Saat siang hari, tidak terlihat ada interaksi antar warga yang terjadi di jalanan karena cuaca yang panas serta banyak warga yang sedang bekerja di luar perumahan. Saat sore sepulang kerja (jam 5) hingga malam hari, jalanan perumahan kembali ramai dengan warga yang berkumpul, baik anak-anak yang bermain maupun warga yang berbincang di depan rumah (Gambar 9).
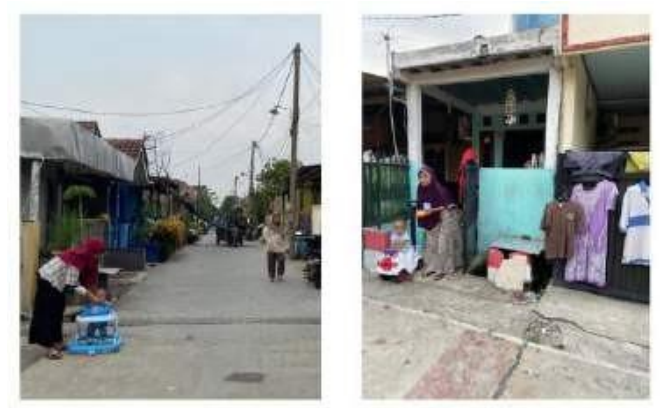

Gambar 8. Sua sana jalan perumahan pagihari
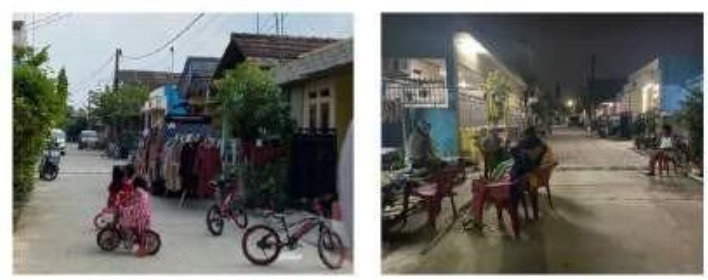

Gambar 9. Suasana jalan perumahan yang kembali ramai saat sore hingga malam hari

Jalanan di dalam perumahan ini telah mengalami banyak perubahan. Paiza Pasaribu merupakan ketua RT 01 Perumahan Bumi Yapemas Indah. Beliau sudah tinggal di perumahan tersebut sejak tahun 1997. Menurut penuturan Beliau, saat perumahan pertama kali dibangun, jalanan di dalam perumahan masih berupa tanah. Beberapa tahun kemudian jalanan mulai diberi aspal secara bertahap dan pada tahun 2018 lalu seluruh jalan di Perumahan Bumi Yapemas dicor beton. Kondisi jalan yang semakin baik meningkatkan kenyamanan warga dan memudahkan aktivitas warga.

Selain kondisi jalan yang semakin membaik, sarana dan prasarana di sekitar lingkungan perumahan semakin berkembang. Menurut penuturan Supriyadi (50 tahun), aksesibilitas perumahan sudah semakin baik. Beliau yang sehari-hari berprofesi sebagai pedagang buku di Pasar Senen, Jakarta, merasa sangat terbantu dengan adanya stasiun kereta api yang berjarak $3 \mathrm{~km}$ dari perumahan (Gambar 10). Tersedianya trasnportasi umum di sekitar 
perumahan memudahkan warga yang rata-rata bekerja di wilayah DKI Jakarta.

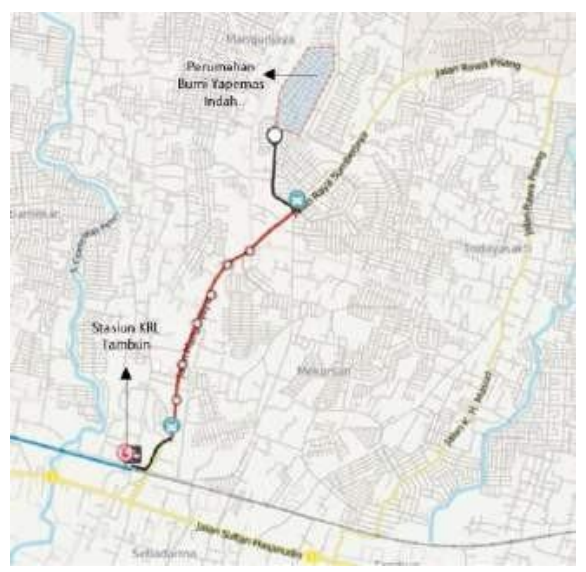

Gambar 10. Letak Stasiun KRL Tambun terhadap Perumahan Bumi Yapemas

Sumber:moovitapp.com dengan disesuaikan penulis, 2020

Masyarakat Perumahan Bumi menjunjung tinggi nilai agama islam dalam kesehariannya Kentalnya nilai-nilai islam dalam kehidupan masyarakat terlihat dari kegiatan keagamaan yang menjadi rutinitas bersama warga. Hal tersebut didukung dengan tersedianya sarana Masjid Al-Hikmah Yapemas Sorkam yang berada dalam perumahan (Gambar 11). Menurut penuturan Eddy (63 tahun), masjid dibangun selain untuk tempat kegiatan ibadah juga untuk menunjukkan indentitas masyarakat Sorkam yang beragama islam. Seiring perkembangan, Masjid menjadi indentitas kawasan dan wadah interaksi warga perumahan dengan warga luar perumahan. Masjid dengan luas $500 \mathrm{~m} 2$ tersebut mewadahi berbagai kegiatan keagaamaan maupun sosial yang dihadiri berbagai kalangan (Gambar 12). Sehari-hari masjid ini ramai digunakan warga untuk sholat berjamaah dan pengajian. Hal ini menjadikan masjid sebagai elemen penting dalam kehidupan warga.

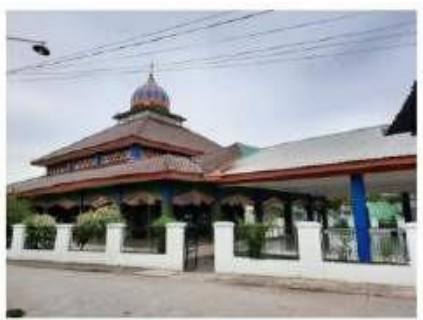

Gambar 11. Masjid Al-Hikmah Yapemas Sorkam yang berada dalam perumahan

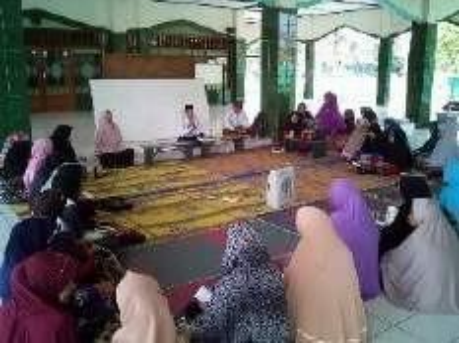

Gambar 12. Sosialisasi Program Gerakan Sejuta Koin Sorkam (GSKS) di Masjid Al-Hikmah Yapemas Sorkam

Sumber: https://www.facebook.com/yapemas, dia mbil pa da tanggal 7 November 2020.

Terdapat 7 lapangan olahraga di dalam Perumahan Bumi Yapemas Indah (3 lapangan voli, 3 lapangan badminton, dan 1 lapangan futsal). Fasilitas tersebut menjadi tempat berkumpul warga khususnya di sore hari. Abdul Hakim (52 tahun) merupakan ketua RT 07 Perumahan Bumi Yapemas Indah. Beliau menuturkan bahwa dengan adanya lapangan sebagai fasilitas olah raga, perumahan menjadi terasa "lebih hidup". Fasilitas olah raga tersebut mendorong munculnya rutinitas berolahraga di perumahan. Sehari-hari, remaja warga perumahan memanfaatkan lapangan tersebut untuk bermain voli dari jam 4 hingga sebelum magrib (Gambar 13). Mereka memanfaatkan faslitias tersebut sepulang sekolah. Di akhir minggu, lapangan digunakan untuk kegiatan senam jantung sehat yang diadakan pengurus RW 09.
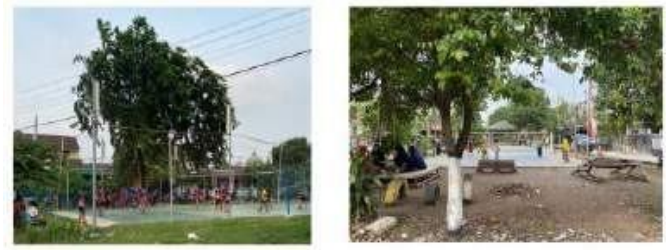

Gambar 13. Lapangan voli diRT 03 (kiri) dan la pangan badminton diRT 06 (kanan) Perumahan Bumi Yapemas Indah

Beliau juga menuturkan terdapat beberapa rumah usaha yang tersebar di perumahan Bumi Yapemas Indah (Gambar 14). Rumah usaha (shophouse) adalah bentuk bangunan yang menggabungkan fungsi hunian dengan fungsi komersial atau usaha di dalamnya secara informal (Nordiana, Wan \& Huda, Noor, 2015; Purwantiasning, 2012). Rumah usaha menyediakan berbagai macam kebutuhan warga mulai dari sembako hingga kuliner. 
Rumah usaha tumbuh dan berkembang secara adaptif dan responsif terhadap peluang perekonomian yang terjadi di dalam masyarakat (Prasetyo, Putra, Rahmaputra \& Ekomadyo, 2020). Beliau menuturkan bahwa rumah usaha ini muncul atas inisiatif warga, terutama para ibu rumah tangga yang ingin membantu perekonomian keluarganya dengan membuka usaha di rumah sembari mengisi waktu luang. Kehadiran rumah usaha ini mendorong adanya rutinitas berbelanja dalam perumahan. Selain itu rumah usaha ini turut menjadi tempat berkumpul warga di sore hari.
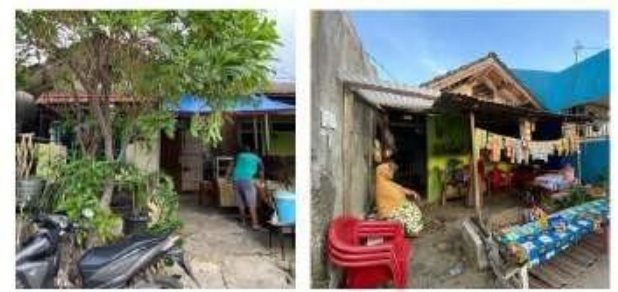

Gambar 14. Beberapa rumah usaha di dalam Perumahan Bumi Yapemas Indah

Dari penuturan kelima warga tersebut, didapat bahwa ritme kehidupan permukiman di Perumahan Bumi Yapemas terbentuk dari adanya elemen-elemen lingkungan binaan dalam perumahan, diantaranya adanya koridor jalan dan akses masuk lingkungan, fasilitas ibadah, fasilitas olah raga, dan rumah usaha di dalam perumahan. Keberadaan elemen tersebut menimbulkan ragam aktivitas yang memperkaya penggunaan ruang dalam lingkungan perumahan. Hal tersebut memberikan nyawa tersendiri pada perumahan. Nyawa dari sebuah ruang itu hadir apabila ada kegiatan ataupun suatu hal menarik di dalamnya (Tamariska \& Ekomadyo, 2017; Cresswell, 2009; Tuan, 1997).

Berdasarkan hasil pengamatan, terdapat ragam aktivitas yang terjadi dalam lingkungan perumahan yang dipetakan dalam tabel 1 . Ragam aktivitas tersebut membentuk ritme permukiman di Perumahan Bumi Yapemas. Dari hasil pengamatan dan wawancara, didapat empat kelompok masyarakat dalam Perumahan Bumi Yapemas Indah berdasarkan aktivitas sehari-hari mereka (Tabel 2). Aktivitas ini membentuk ritme bagi masing-masing kelompok masyarakat (Gambar 15).

Tabel 1. Ragam aktivitas dan suasana sepanjang haridi Perumahan Bumi Yapemas Indah

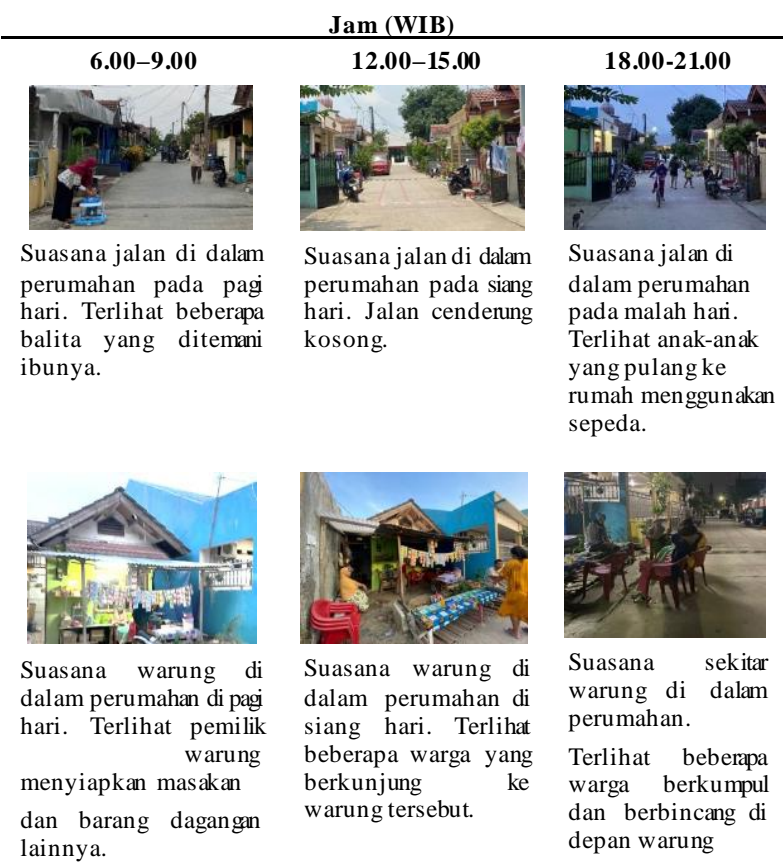

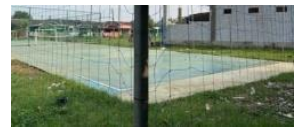

Suasana lapangan olahraga di pagi hingga siang hari. Tidak terlihat ada warga yang menggunakan lapangan olah raga

Tabel 2. Kegiatan sehari-hari warga Penumahan Bumi Yapemas Indah

\begin{tabular}{|c|c|c|c|}
\hline $\begin{array}{c}\text { ibu rumah } \\
\text { tangga }\end{array}$ & balita & anak sekolah & $\begin{array}{c}\text { pekerja dan } \\
\text { pedagang }\end{array}$ \\
\hline $\begin{array}{l}\text { bangun \& } \\
\text { mengerjakan } \\
\text { pekerjaan } \\
\text { rumah (a1) }\end{array}$ & $\begin{array}{l}\text { bangun, } \\
\text { bermain di } \\
\text { luar rumah \& } \\
\text { berjemur (b1) }\end{array}$ & $\begin{array}{l}\text { bangun, } \\
\text { mengerjakan } \\
\text { pekerjaan } \\
\text { rumah }(\mathrm{c} 1)\end{array}$ & $\begin{array}{l}\text { bangun, } \\
\text { bersiap } \\
\text { berangkat } \\
\text { kerja }(\mathrm{d} 1)\end{array}$ \\
\hline $\begin{array}{l}\text { berbelanja ke } \\
\text { pasar (a2) }\end{array}$ & $\begin{array}{l}\text { bermain di } \\
\text { dalam rumah, } \\
\text { tidur siang (b2) }\end{array}$ & $\begin{array}{l}\text { belajar (secara } \\
\text { daring) (c2) }\end{array}$ & $\begin{array}{l}\text { berangkat } \\
\text { kerja, bekerja/ } \\
\text { berdagang } \\
\text { (d2) }\end{array}$ \\
\hline $\begin{array}{l}\text { menjaga anak } \\
\text { bermain (a3) }\end{array}$ & $\begin{array}{l}\text { bermain di luar } \\
\text { rumah (b3) }\end{array}$ & $\begin{array}{l}\text { berkumpul, } \\
\text { bermain di } \\
\text { lapangan olah } \\
\text { raga }(\mathrm{c} 3)\end{array}$ & $\begin{array}{l}\text { pulang kerja } \\
\text { (d3) } \\
\text { istirahat, } \\
\text { berkumpul } \\
\text { dengan } \\
\text { tetangga, olah } \\
\text { raga (d4) } \\
\end{array}$ \\
\hline $\begin{array}{l}\text { mengerjakan } \\
\text { pekerjaan } \\
\text { rumah (a4) }\end{array}$ & $\begin{array}{l}\text { kembali ke } \\
\text { rumah, } \\
\text { bermain di } \\
\text { dalam rumah } \\
\text { (b4) } \\
\end{array}$ & $\begin{array}{l}\text { kembali ke } \\
\text { rumah, } \\
\text { mengerjakan } \\
\text { tugas }(\mathrm{c} 4)\end{array}$ & $\begin{array}{l}\text { kembali ke } \\
\text { rumah, } \\
\text { istirahat (c4) }\end{array}$ \\
\hline $\begin{array}{l}\text { berkumpul } \\
\text { dengan } \\
\text { tetangga (a5) }\end{array}$ & istirahat (b5) & istirahat (c5) & \\
\hline \multicolumn{4}{|l|}{$\begin{array}{l}\text { mengerjakan } \\
\text { pekerjaan } \\
\text { rumah (a6) }\end{array}$} \\
\hline istirahat (a7) & & & \\
\hline
\end{tabular}




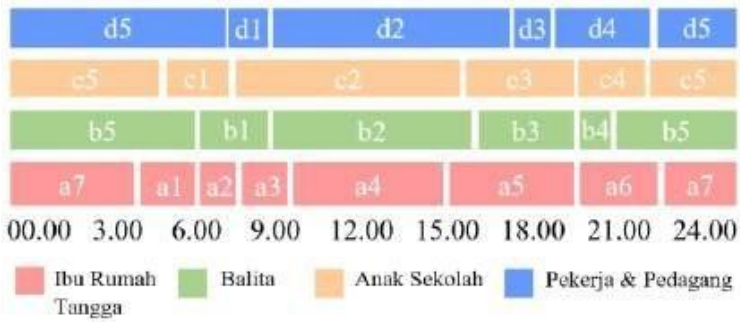

Gambar 15. Ilustrasi ritme kehidupan warga perumahan

Ritme kelompok ini berjalan linear dan berdampingan. Keempat kelompok masyarakat memiliki keseharian yang berbeda sehingga ritme kehidupannya pun berbeda. Namun tidak seluruh keseharian kelompok masyarakat ini berbeda, ada persinggungan aktivitas lewat penggunaan ruang secara bersama. Persinggungan ini menjadi tanda akan adanya harmonisasi ritme yang membentuk setting ritme permukiman menjadi satu keutuhan (cyclical). Harmonisasi ini membentuk interaksi antarritme kehidupan warga sehingga terjadi penguatan fenomena penggunaan ruang sesuai dengan konsep eurhythmia.

\subsection{Pengaruh Budaya Masyarakat Sorkam Terhadap Penggunaan Ruang di Perumahan Bumi Yapema}

Dari hasil wawancara, seluruh responden mengatakan bahwa mereka nyaman dan aman tinggal di Bumi Yapemas. Kenyamanan tersebut muncul karena merasa dalam komunitas dengan etnis yang sama, dengan begitu dari segi budaya dan kebiasaan cenderung sama. Responden merasa dengan begitu lebih bebas dalam beraktivitas dan ada rasa percaya terhadap satu sama lain sehingga menimbulkan rasa aman. Hal ini serupa dengan temuan Weng (2018) bahwa latar belakang yang seragam menimbulkan rasa aman dan nyaman sehingga menjadi pertimbangan utama dalam memilih hunian. Penggunaan bahasa daerah yang masih sering digunakan oleh mayoritas warga membuat komunikasi lebih mudah dan lugas. Tingkat kenyamanan yang tinggi akibat faktor sosial ini membuat warga betah tinggal di perumahan ini. Dari hasil wawancara semua responden berkata bahwa tidak pernah berencana untuk pindah ke kawasan lain.
Responden memilih melakukan renovasi atau penyesuaian lainnya dibandingkan mencari rumah dengan fasilitas yang lebih baik. Febrida (34 tahun) lebih memilih untuk mengontrak rumah di Perumahan Bumi Yapemas Indah daripada tinggal di rumah aslinya di daerah Cikarang dan Cibitung. Ibu Febrida memilih tinggal di perumahan ini karena memiliki mertua dan sanak saudara yang tinggal di perumahan tersebut. Beliau menuturkan bahwa karena Bumi Yapemas ditempati oleh mayoritas masyarakat asal Sorkam yang sudah dianggap saudara, maka beliau merasa aman meninggalkan rumahnya tanpa penjagaan. Faktor kesamaan budaya dan ikatan persaudaraan yang kuat ini juga menimbulkan rasa aman bagi warganya.

Di perumahan ini komunitas masyarakat membawa budaya dan kebiasaan dari kampung halaman mereka. Salah satu yang masih dilestarikan di daerah tersebut salah satunya kesenian Sikambang. Kesenian ini ditampilkan saat rombongan warga mengiringi pengantin di jalanan perumahan (Gambar 16). Koridor jalan menjadi wadah interaksi antar warga.
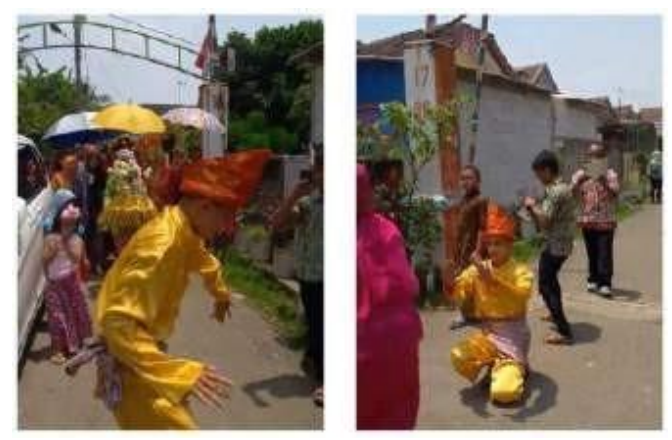

Gambar 16. Kesenian Sikambang mengiringi pengantin di sepanjang jalan perumahan

Dalam kehidupan sehari-hari, koridor jalan perumahan juga dimanfaatkan sebagai ruang sosial bagi warga setempat. Warga menjadikan koridor jalan sebagai ruang interaksi sosial berdasarkan kebiasaan berkumpul warga (Tamariska \& Ekomadyo, 2017). Riska (41 tahun), Ketua PKK menuturkan bahwa warga biasa berkumpul di depan rumah setiap sore hingga malam hari (Gambar 17). Dari hasil pengamatan, ditemukan beberapa warga yang sengaja 
meninggalkan kursi di pinggir jalan untuk digunakan saat sore hari (Gambar 18). Koridor jalan perumahan dimanfaatkan sebagai eksteknsi dari teras rumah.
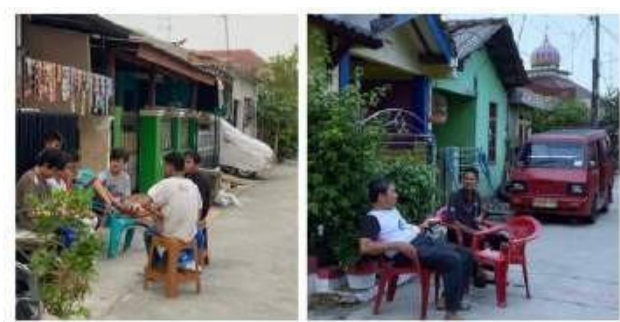

Gambar 17. Suasana warga y ang duduk dan berbincang di pinggir ja lan

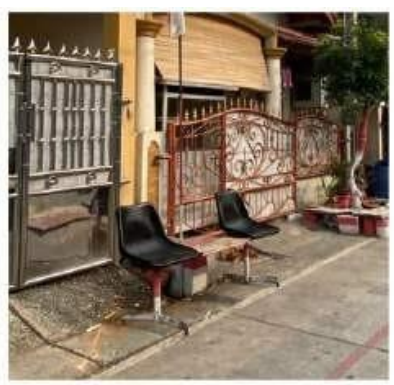

Gambar 18. Penambahan kursi di pinggir ja lan perumahan

\subsection{Adaptasi Hunian di Perumahan Bumi Yapemas Indah}

Tidak ditemukan jejak arsitektur tradisional pada bentuk rumah karena pengembang mengadopsi tipe rumah sangat sederhana standar yang biasa dibangun oleh para pengembang (Gambar 19). Ritme kehidupan masing-masing warga mendorong dilakukannya adaptasi spasial dalam hunian mereka. Warga merenovasi rumah mereka dengan mengatur ulang tata letak maupun menambahkan ruangan di dalam rumah.

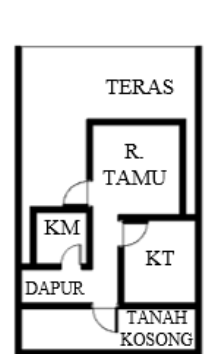

(a)

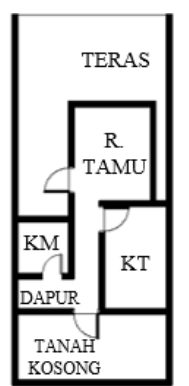

(b)
Gambar 19. Denah awal rumah tipe 27 di lahan berukuran $6 \times 10 \mathrm{~m}$ (a) dandenah a wal rumah tipe 27 di lahan berukuran $5 \times 12 \mathrm{~m}$ (b)
Nur Sahidah (50 tahun) merupakan salah satu warga RT 07. Sehari- hari Ibu Sahidah memasak dan menjual kue tradisional Sorkam di perumahan Bumi Yapemas dan sekitarnya. Keseharian beliau dimulai dengan menyiapkan bahan masak di sore hari dilanjutkan dengan memasak hingga jam 3 pagi. Kemudian beliau membagikan kue-kue tersebut pada ibu-ibu warga setempat yang yang akan berkeliling berjualan kue. Beliau melakukan penyesuaian pada rumahnya dengan merombak bagian depan rumahnya menjadi dapur kedua yang dimanfaatkan untuk memasak kue (Gambar 20). Beliau memilih untuk memanfaatkan bagian depan rumahnya sebagai dapur agar mudah untuk digunakan bersama ibu-ibu lainnya yang membantu proses masak. Dengan begitu, proses masak tidak mengganggu anak dan suami beliau yang sedang beristirahat di dalam rumah. Dengan menempatkannya di area luar rumah, dapur menjadi mudah dibersihkan.
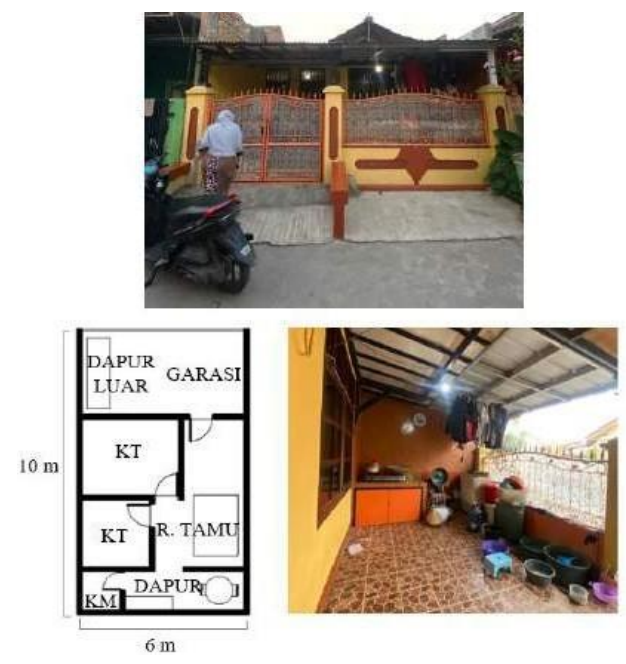

Gambar 20. Tampak depan rumah Nur Sahidah (atas), denah rumah (kiri), Area dapur luar ruangan (kanan)

Ibu Febrida (34 tahun) merupakan salah satu warga RT 06. Beliau mengontrak rumah di Bumi Yapemas Indah sejak tahun 2007. Sebelumnya beliau mengontrak di RT 07 kemudian pindah ke RT 03 pada tahun 2013. Sehari-hari beliau berjualan mie daging bersama suaminya. Beliau melakukan penyesuaian pada rumahnya dengan menambahkan bangku dan etalase untuk 
berjualan (Gambar 21). Rumah beliau tidak berpagar sesuai dengan desain asli dari rumah perumahan tersebut. Bagian depan rumah yang terbuka memudahkan beliau berjualan. Tidak adanya pagar membuat kesan rumah yang lebih terbuka.
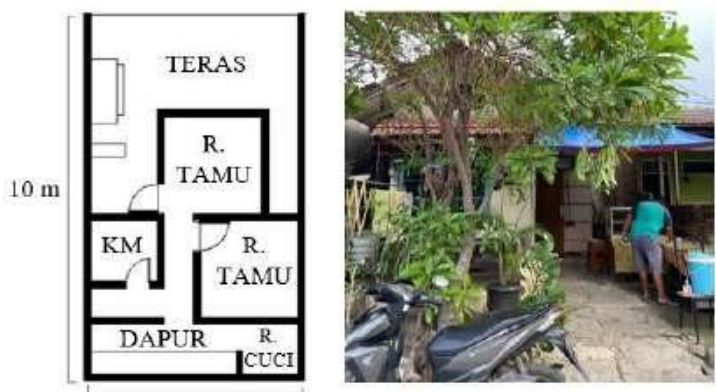

$6 \mathrm{~m}$

Gambar 21. Denah rumah Ibu Febrida (kiri), Area depanrumah (kanan)

Nur Aini (51 tahun) merupakan ibu rumah dan aktif dalam kegiatan masyarakat. Beliau sudah menempati rumah sejak tahun 1997 dan telah melakukan beberapa perubahan (Gambar 22). Beliau memperluas area ruang tamu, untuk mengakomodasi kegiatan pengajian bagi warga setempat. Kegiatan pengajian menjadi sesuatu yang penting karena nilai-nilai Islam menjadi dalam kehidupan sehari-hari masyarakat. Saat ada pengajian, perabot seperti sofa dan meja dipindahkan ke teras depan, sehingga 40 orang dapat tertampung. Selain itu, Beliau juga memindahkan letak kamar mandi dan dapur ke area belakang agar ruangan terasa lebih luas.
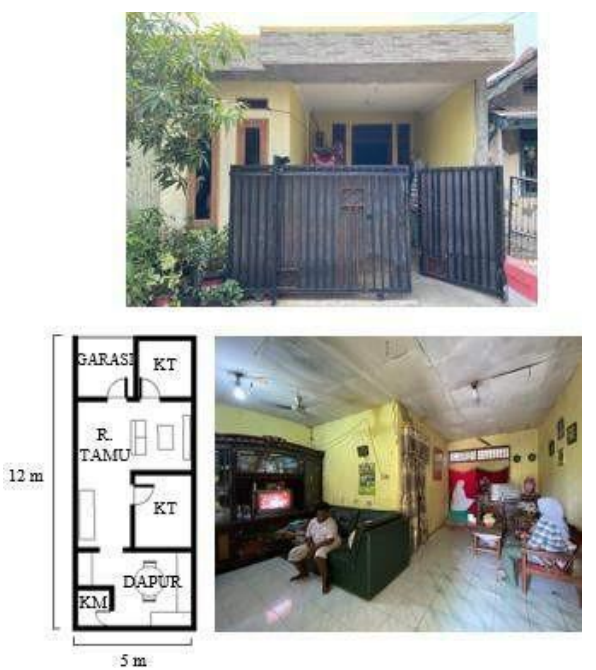

Gambar 22. Tampak depan rumah Nur Aini (atas), denahrumah (kiri), Area ruang tamu rumah (kanan)
Sahraini (48 tahun) merupakan salah satu warga RT 01. Sama seperti Nur Aini, Beliau juga memperluas area ruang tamu rumahnya untuk mengakomodasi kegiatan pengajian dan menampung banyak tamu (Gambar 23). Saat acara pengajian berlangsung, rumah Ibu Sahraini dapat menampung hingga 60 orang. Beliau memilih untuk menggelar karpet saja dibandingkan menambah perabot sofa dan meja dengan alasan agar terasa lebih luas dan tidak perlu memindahkan perabot tersebut saat menyelenggarakan arisan.
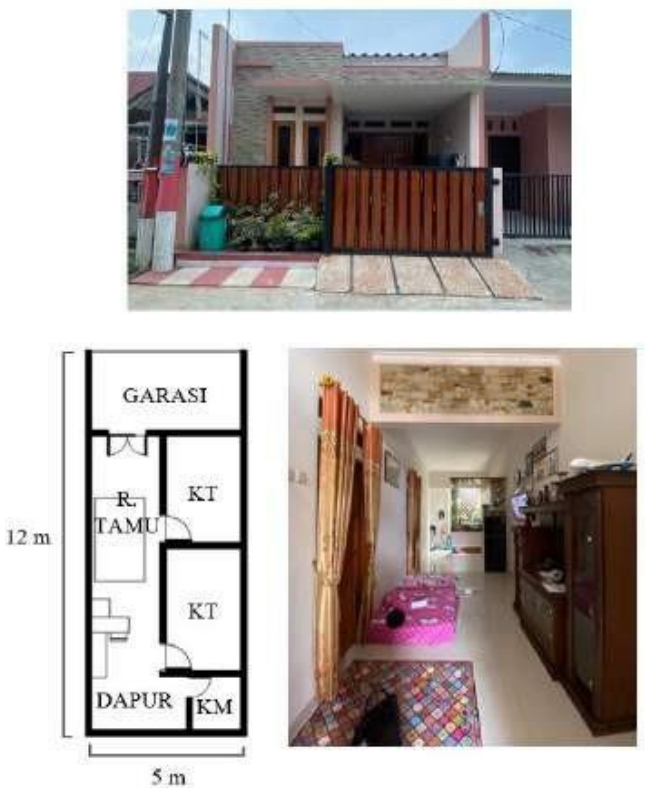

Gambar 23. Tampak depan rumah Sahraini (atas), denah rumah (kiri), Area ruang tamu rumah

(kanan)

Paiza (48 tahun), ketua RT 01, memperluas rumahnya dengan menggabungkan dua rumah menjadi satu. Tujuannya untuk mendapatkan kamar tambahan untuk anak dan mertuanya. Beliau meletakkan ruang tamunya di tengah rumah dengan layout terbuka. Sama seperti Ibu Sahraini, beliau memilih untuk menggelar karpet agar ruangan dapat menampung banyak orang dan tidak perlu memindahkan perabot saat menyelenggarakan arisan. Selain itu, beliau memperluas area garasi agar dapat memarkirkan mobilnya (Gambar 24). 

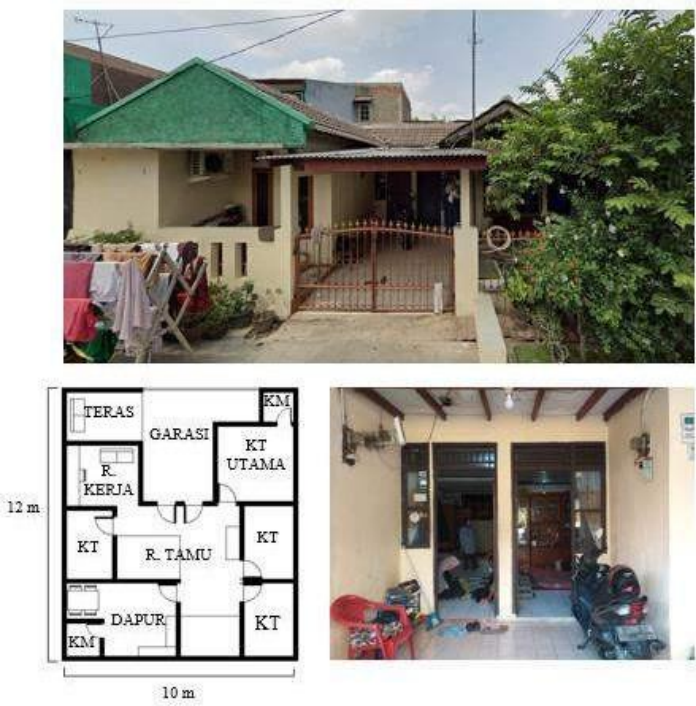

Gambar 24. Denah rumah Ibu Paiza (kiri), Area teras dan ruang tamu rumah (kanan)

\section{KESIMPILAN}

Ritme kehidupan di Perumahan Bumi Yapemas terbentuk dari adanya elemen- elemen lingkungan binaan dalam perumahan, diantaranya adanya jalan dan akses masuk lingkungan, fasilitas ibadah, fasilitas olah raga, dan rumah usaha di dalam perumahan. Keberadaan elemen tersebut menimbulkan ragam aktivitas yang memperkaya penggunaan ruang lingkungan perumahan sehingga membentuk ritme permukiman.

Tidak ditemukan adanya adat istiadat tertentu yang diterapkan dalam keseharian masyarakat. Budaya tradisional yang masih diterapkan hanya berupa kesenian dan upacara yang bersifat sesekali sehingga tidak berpengaruh terhadap budaya bermukim masyarakat yang sehari-hari sudah modern. Budaya tradisional masyarakat Sorkam tidak berpengaruh langsung terhadap arsitektur maupun penggunaan ruang dalam keseharian warga Perumahan Bumi Yapemas Indah. Namun, kesamaan budaya masyarakat mendorong interaksi antar ritme kehidupan warga yang menimbulkan fenomena penggunaan ruang sesuai dengan konsep eurhythmia.

Fenomena penggunaan ruang yang pertama yaitu timbulnya rasa aman dan nyaman yang membuat masyarakat menggunakan ruang dengan leluasa. Tingkat kenyamanan dan rasa aman yang tinggi akibat faktor sosial ini membuat warga betah tinggal di perumahan ini.
Fenomena kedua yaitu adanya pemanfaatan ruang luar dan dalam sebagai ruang sosial. Ruang luar berupa koridor jalan dimanfaatkan warga perumahan sebagai tempat untuk berkumpul dan berbincang di sore hari, sedangkan ruang dalam berupa ruang tamu rumah dimanfaatkan sebagai tempat untuk mengadakan arisan dan pengajian. Fenomena ketiga yaitu adanya penyesuaian hunian sesuai dengan budaya masyarakat setempat. Penyesuain hunian berupa perubahan tata letak ruang maupun furnitur dalam ruangan.

Penelitian ini diharapkan bisa berkontribusi pada kajian ruang dan tempat (space and place) dalam perspektif konstruksi sosial (Morgan, 2010). Perspektif ini melihat ruang merupakan wujud representasi dari apa yang diperjuangkan sekelompok masyarakat (Lefebvre, 1974/1991, Ekomadyo, dkk., 2017) dan menjadi delegasi dari perhatian dari kelompok masyarakat ini (Ekomadyo \& Yuliar, 2014, Ekomadyo \& Riyadi, 2020). Kajian sosio-spasial ini penting dalam perhatian akan aspek kemanusiaan dalam kajian lingkungan binaan.

\section{UCAPAN TERIMAKASIH}

Penulis mengucapkan terima kasih kepada Eddy Pasaribu selaku ketua RW 09 Desa Sumber Jaya dan Paiza Pasribu selaku ketua RT 01 RW 09 Desa Sumber Jaya yang telah membantu peneliti dalam pengambilan data. Penulisjuga mengucapkan terima kasih kepada warga Perumahan Bumi Yapemas Indah atas sambutan hangat serta kesediaanya untuk memberikan data yang dibutuhkan.

\section{REFERENSI}

Ata, M., \& Ekomadyo, A. S. (2018). Adaptasi Arsitektur Tradisional Bali Pada Tempat- Tempat Komunal Di Desa Balinuraga, Kalianda, Lampung Selatan. Jurnal Koridor, 9(2), 312-321.

Alahdeff-Jones, Michel. (2019). Beyond Space and Time - Coceiving the Rhythmic Configurations of Adult Education through Lefebvre's rhythmanalysis. ZfW 42, 165-181 (2019). https:// doi.org/10.1007/s40955-019-0133-0

Ben-Arieh, Yehoshua (1984). Jerusalem in the 19th Century, The Old City. Yad Izhak 
Ben Zvi \& St. Martin's Press. p. 14. ISBN $0-312-44187-8$.

Cresswell, Tim. (2009). Place: A Short Introduction. Royal Holloway, University of London, Egham, UK.

Ekomadyo, A.S., and Riyadi, A. (2020). Design in Socio-technical Perspective: An Actor-Network Theory Reflection

on Community Project 'Kampung Kreatif' in Bandung, Archives of Design Research, Volume: 33 Issue: 2, Page: 1937 ,

doi:https://doi.org/10.15187/adr.2020.05 .33.2.19.

Ekomadyo, A.S., dan Yuliar, S. (2014) Social Reassembling as Design Strategies. ArtePolis 5, Science Direct - Procedia Social and Behavioral Sciences 184(2015) 152-160, 1877-0428 (C) 2015, doi: $10.1016 /$ j. sbspro.2015.05.075

Ekomadyo, A.S., Santri, T., Riyadi, A (2017). Reassembling Traditionality and Creativity? A Study of Creative Community Movement in Cihapit Market Bandung. International Conference of Architectural Education in Asia

(Eduarchsia).https://doi.org/10.1051/shs c onf/20184107006.

Ellisa, A. (2008). Pekojan: Between the disappearance of Muslim Arabs and the emergence of Chinese communities. Vernacular Building Types and Settlements in Transition (4th International Seminar On Vernacular Settlement) Ahmedabad, India, February 14-17, 2008. ISBN 978-81-906399-0-3.

Doxiadis, C. A. (1969). Ekistics: the Science of Human Settlements. London.

Hopkins, I. W. J. (1971). The Four Quarters of Jerusalem. Palestine Exploration Quarterly, 103(2), 68-84. doi:10.1179/peq.1971.103.2.68

Kurniadi, Ardi, and Tin B. Utami. (2016). Tipologi Fasad Bangunan pada Penggal Jalan Permukiman Perkotaan Kasus: Kampung Arab Pekojan, Jakarta Barat. Vitruvian: Jurnal Arsitektur, Bangunan dan Lingkungan, vol. 5, no. 3, 2016.

Kumar, Ranjit. (2005). Research Methodology: A Step by Step Guide for Beginners.
Frenchs Forest, N.S.W: Pearson Longman.

Lefebvre, H. (1974/1991) The Production of Space. Blackwell, Oxford.

Lefebvre, Henry. (2004). Rhythmanalysis: Space, time and everyday life. London: Continuum.

Lyon, Dawn. (2016). Doing Audio-Visual Montage to Explore Time and Space: The Everyday Rhythms of Billingsgate Fish Market. Sociological Research Online, $21 \quad$ (3), 12 DOI: 10.5153/sro.3994

Morgan, Paul (2010). Towards a developmental theory of place attachment. Journal of Environmental Psychology. Volume 30, Issue 1, March 2010, Pages 11-22.

Nash, Louise. (2018). Performing Place:A Rhythmanalysis of the City of London. Organization Studies 1-21.

Nasser, R., Sulasman, S., \& Akbar, M. H. (2020). Perkembangan komunitas Arab di Indonesia: Studi kasus perkampungan masyarakat Arab di Pekojan Jakarta Barat pada tahun 1950-2018. Historia Madania: Jurnal Ilmu Sejarah, 4(2), 247-268.

Nordiana, Wan \& Huda, Noor. (2015). An Overview on the Typology of Shophouses' Facade at the Heritage Area in Ipoh City. Proceedings of Postgraduate Conference on Global Green Issues (Go Green), UiTM (Perak), Malaysia, 7-8 October 2015. DOI: 10.13140/RG.2.1.1937.0962

Peng-Lee, Siew. (2016). Ethnography in Absentia: Applying Lefebvre's Rhythmanalysis In Impossible-toResearch Spaces. Ethnography 0(00) 120. DOI: $10.1177 / 1466138116641438$.

Purwantiasning, Ari Widyati. (2012). Kajian tentang Alih Fungsi Hunian Menjadi Tempat Usaha. Jurnal Ilmiah Desain dan Konstruksi $11 \quad$ (2).

https://ejournal.gunadarma.ac.id/index.p $\mathrm{h}$ p/dekons/article/view/1001.

Prasetyo, Eko Bagus, Andrew Cokro Putra, Bima Rahmaputra, dan Agus Suharjono Ekomadyo. (2020). Strategi Adaptasi Arsitektural Pada Rumah Usaha Di Jalan Tubagus Ismail, Bandung. ARTEKS : Jurnal Teknik Arsitektur 5 (1), 7-16. https://doi.org/10.30822/arteks.v5i1.72. 
Sinar, Syaiful A. Tandjung, \& Marwansyah Putra. (2010). Mengenal Adat dan Budaya Pesisir Tapannuli Tengah Sibolga. Medan:Forkala. ISBN 978-97999315-8-0

Tamariska, S. R., \& Ekomadyo, A. S.(2017). Place-Making Ruang Interaksi Sosial Kampung Kota: Kasus: Koridor Jalan Tubagus Ismail Bawah, Bandung. Jurnal Koridor, 8(2), 172-183.

https://doi.org/10.32734/koridor.v82.134 $\underline{5}$.

Tuan, Y.F. (1977). Space and Place: The Perspective of Experience. Minneapolis, MN: University of Minnesota Press.

Wahyudi, J., \& Madjid, D. (2019). Pekojan: Image of an Arab Kampong XVIII to XIX Centuries Batavia. Insaniyat: Journal of Islam and Humanities, 3(2), 99-110.

Weng, H. W. (2018). Islamic ways of Modern Living In Hellman, Marie Thynell, \& Roanne van Voorst (Ed), Jakarta: Claiming Spaces And Rights in The City, pp. 95. Routledge. ISBN 9780367592554. 